\title{
An Uncommon Cause of Hypernatremia in Very Low Birth Weight Premature Infants: Idiopathic Central Diabetes Insipidus
}

\author{
Selma Aktas' (D), Ebru Kazancı' (D), Serap Semiz² (D), Ayşe Korkmaz' (D) \\ 'Division of Neonatology, Department of Pediatrics, Acıbadem Mehmet Ali Aydınlar University Faculty of Medicine, i̇stanbul, Turkey \\ ${ }^{2}$ Division of Pediatric Endocrinology, Department of Pediatrics, Acıbadem Mehmet Ali Aydınlar University Faculty of Medicine, İstanbul, Turkey
}

ORCID iDs of the authors: S.A. 0000-000I-7858-7292; E.K. 0000-0002-7920-852X; S.S. 0000-0002-197I-40I7; A.K. 0000-0003-4934-II24.

Cite this article as: Aktas S, Kazancı E, Semiz S, Korkmaz A. An Uncommon Cause of Hypernatremia in Very Low Birth Weight Premature Infants: Idiopathic Central Diabetes Insipidus. Cyprus J Med Sci 2021; 6(2): I77-179.

\begin{abstract}
Central diabetes insipidus (CDI) is a water homeostasis disorder characterized by an inability to concentrate urine because of insufficient production of antidiuretic hormone. Dehydration with hypernatremia can occur during the neonatal period in preterm neonates in association with insensible water loss, high urine output, and reduced sodium excretion. A high index of suspicion is required to diagnose CDI in preterm neonates. We report two cases, who presented persistent hypernatremia with polyuria despite increased fluid supply and low sodium intake. CDI diagnosis was confirmed by the therapeutic test with oral vasopressin analog. Investigations were all normal; $C D I$ was considered idiopathic. Persistent hypernatremia despite increased fluid intake with polyuria, hyposthenuria, low urine output, and high plasma osmolality is the key point for the diagnosis.
\end{abstract}

Keywords: Central diabetes insipidus, premature infants

\section{INTRODUCTION}

Diabetes insipidus (DI) is a water homeostasis disorder characterized by an inability to concentrate urine because of insufficient production of antidiuretic hormone $(A D H)$ (central diabetes insipidus, $C D I$ ) or due to impaired kidney response to $\mathrm{ADH}$ (nephrogenic diabetes insipidus).', $\mathrm{CDI}$ in a neonate is usually associated with congenital abnormalities of the central nervous system, hypoxic-ischemic encephalopathy, meningitis, encephalitis, or severe intraventricular hemorrhage $(\mathrm{IVH})$ in preterm neonates. ${ }^{3}$ During neonatal period, dehydration with hypernatremia can occur due to insensible water loss, high urine output, and reduced sodium excretion in preterm neonates. Therefore, a high index of suspicion is required to diagnose CDI in very low birth weight infants. ${ }^{2-4}$

To alert for CDI diagnosis and early treatment in the neonatal period, two cases of very low birth infants with idiopathic CDI, who were successfully controlled through lyophilized sublingual desmopressin, were reported.

\section{CASE PRESENTATION \\ Case I}

A male preterm neonate with a gestational age of 31 weeks and a birth weight of $1215 \mathrm{~g}$ was born by cesarean section (C/S) with Apgar scores of 4 and 7 at Ist and 5th minutes, respectively. He was on nasal intermittent positive-pressure ventilation and did not require surfactant therapy. Antibiotic therapy was begun because of high CRP level. On the 5th day of life due to increase in CRP, oxygen requirement $\left(\mathrm{FiO}_{2}>40 \%\right)$, and respiratory acidosis, he was intubated, surfactant was given, and antibiotic treatment was changed. He was extubated the next day followed by noninvasive ventilation for 2 weeks. On the 13th day of life, although the daily Na intake was $1.2 \mathrm{meq} \mathrm{kg}^{-1} \mathrm{~d}^{-1}$ and the daily fluid supply

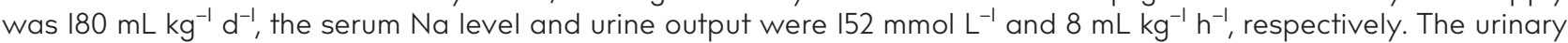
and plasma osmolalities were 98 and $302 \mathrm{mOsm} \mathrm{kg}^{-1}$, respectively. The density of urine was around I005. The ADH

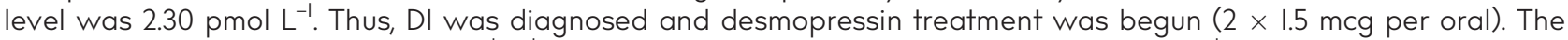
urine output decreased to $4-5 \mathrm{~mL} \mathrm{~kg}^{-1} \mathrm{~h}^{-1}$, and the plasma Na level decreased to $140 \mathrm{mmol} \mathrm{L}^{-1}$. Transfontanelle sonography did not demonstrate IVH. The evaluation of the pituitary axes revealed normal thyroid, adrenal, and gonadal functions. Serological tests for syphilis, toxoplasmosis, cytomegalovirüs, herpes simplex, and rubella (TORCHS) ruled out 
these congenital infections. No abnormalities were observed in serum urea nitrogen, creatinine, potassium, calcium, and bicarbonate levels. Magnetic resonance imaging (MRI) of the brain was planned to evaluate pituitary gland and the other structures of the brain, but parents did not approve it because of sedation. The etiology remains unknown. He was discharged on postnatal on 52nd day of life, at 38/4 corrected age, weighing $2285 \mathrm{~g}$, with a prescription of $2 \times 1.5 \mathrm{mcg}$ of oral desmopressin per day.

\section{Case 2}

A male preterm neonate with a gestational age of 31 weeks and a birth weight of $1015 \mathrm{~g}$ was born by C/S with Apgar scores of 4 and 7 at Ist and 5 th minutes, respectively. He was intubated in the delivery room, surfactant was given for the diagnosis of respiratory distress syndrome, and then extubated followed by noninvasive ventilation for 10 days. On the 12th day of life, respiratory distress reappeared and oxygen requirement increased $\left(\mathrm{FiO}_{2} 40 \%\right)$. He was thought to develop pneumonia and re-intubated. He was extubated on the next day followed by noninvasive ventilation for 2 weeks. On the 24th day of life, we noticed that the urine output (7.78 $\mathrm{mL} \mathrm{kg} \mathrm{k}^{-1}$ ) and plasma $\mathrm{Na}$ level were high, while he was receiving Na supply at a maintenance dose of 3 meq $\mathrm{kg}^{-1} \mathrm{~d}^{-1}$. The urine osmolality was low (I53 $\mathrm{mOsm} \mathrm{kg}{ }^{-1}$ ), serum osmolality (292 $\left.\mathrm{mOsm} \mathrm{kg}^{-1}\right)$, and plasma Na level ( $\left.146 \mathrm{mmol} \mathrm{L}^{-1}\right)$ were high. DI was thought and lyophilized sublingual desmopressin $(2 \times 3 \mathrm{mcg})$ was begun. After treatment, the serum $\mathrm{Na}$ level was between 139 and $142 \mathrm{mmol} \mathrm{L}^{-1}$, and the urine output decreased to 4-5 $\mathrm{mL} \mathrm{kg}^{-1} \mathrm{~d}^{-1}$. Due to desmopressin response, CDI diagnose was made. Transfontanelle sonography did not demonstrate IVH. The evaluation of pituitary axes revealed normal thyroid, adrenal, and gonadal functions. Serological tests for TORCHS were normal. No abnormalities were observed in serum urea nitrogen, creatinine, potassium, calcium, and bicarbonate levels. Desmopressin was used for 23 days. Before discharge, we stopped desmopressin treatment. After 2 days without desmopressin treatment, the urine density was I0I5, and plasma and urine osmolalities were 281 and 123 mOsm $\mathrm{kg}^{-1}$, respectively; the plasma $\mathrm{Na}$ and plasma $\mathrm{ADH}$ levels were $142 \mathrm{mmol} \mathrm{L}^{-1}$ and $3.41 \mathrm{pmol} \mathrm{L}^{-1}$. Therefore, the patient was discharged without treatment. Ten days after discharge, the serum $\mathrm{Na}$ level and urine density were $141 \mathrm{mmol} \mathrm{\textrm {L } ^ { - 1 }}$ and 1010 , respectively. CDI disappeared, but the etiology remained unknown.

\section{DISCUSSION}

In very-low-birth weight infants, fluid-electrolyte homeostasis in the first week of life is generally characterized by low urine

\section{Main Point}

- Central diapedes insipidus is rare and diagnosis is difficult in preterm infants.

- Persistent hypernatremia, dehydration and polyuria beyond first week of life should alert neonatologists.

- Oral desmopressin should be started as soon as the diagnosis is suspected.

- This treatment should be begun with low dosage and be closely monitored. output in the first few days and polyuria thereafter. This causes physiological weight loss and an increase in the serum $\mathrm{N}$ concentration, which is aggravated by transepidermal water loss. Generally, this diuretic phase gets over by the end of the first week of life, and hypernatremia is rare thereafter. ${ }^{5}$ Persistent hypernatremia despite increased fluid intake with polyuria, hyposthenuria, low urinary osmolality, and high plasma osmolality should alert the clinician for the diagnosis of DI. ${ }^{6}$ In present cases, despite the increase in the total fluid intake, patients' serum $\mathrm{Na}$ and urine outputs remained elevated. The detection of low urine osmolality with high serum osmolality and good response to desmopressin confirmed the CDI diagnosis. Until now, underlying causes of $C D I$ reported are intraventricular hemorrhage, meningitis, septo-optic dysplasia, Listeria monocytogenes sepsis, congenital cytomegalovirus infection, midline intracranial defects, and following surgical resection of a suprasellar mass. ${ }^{7-9}$ Idiopathic CDI accounts for $12-24 \%$ of the cases, $^{8-10}$ but idiopathic CDI prevalence in premature infants is higher. ${ }^{10}$ Diagnostic work-up, including the level of hypothalamic-pituitary axis hormones, infectious causes such as serological tests for TORCHS of present cases, were all normal. Transfontanelle sonography revealed no intraventricular hemorrhage.

ADH analog-desmopressin, which is available in three different forms, namely, oral, parenteral, and intranasal preparations, is used to reduce urine output and to decrease serum $\mathrm{Na}$ levels to normal range." Many studies recommended oral desmopressin lyophilisate because of its efficiency, ease of use, and better tolerance. 1012,13 Regardless of the route, treatment requires careful adjustment of dose as neonates rely on liquid diet and desmopressin may cause fluid overload with wide fluctuations in serum $\mathrm{Na}$ levels. Thus, beginning with low dosage twice a day and then increasing according to serum $\mathrm{Na}$ levels and urine output should be better.", I2 Both the cases were treated with sublingual lyophilized desmopressin twice a day. Similarly, Ozaydın et al. ${ }^{14}$ and Atasay et al..$^{15}$ used sublingual desmopressin lyophilisate at a dosage of $2.5 \mu \mathrm{g} \mathrm{kg}^{-1} \mathrm{~d}^{-1}$ to manage CDI in very low birth weight premature infants.

Karthikeyan et al. ${ }^{10}$ reported the first case series of CDI. The most common cause was septo-optic dysplasia but of note idiopathic isolated CDI was diagnosed in three of every premature infants. None of the preterm infants had significant intracranial hemorrhage. The median serum $\mathrm{Na}$ and serum and urine osmolalities at diagnosis were $156 \mathrm{mmol} \mathrm{L}^{-1}$ (range: 145 175), 320 (range: 300-345) and $112 \mathrm{mOsm} \mathrm{kg}^{-1}$ (range: 66-322), respectively, as reported cases.

In conclusion, polyuria despite increased fluid intake, hyposthenuria, low urinary, and high plasma osmolality and persistent hypernatremia are the key points for the diagnosis.

\section{Ethics Committee Approval: N/A}

Informed Consent: A written informed consent was obtained from the parents of the neonates.

Peer-review: Externally peer-reviewed.

Author contributions: Concept - A.S.; Supervision - A.K.; Resource - E.K.; Materials - E.K., A.S.; Data Collection and/or Processing - A.S., E.K.; Analysis and/or Interpretation - A.S., E.K., A.K.; Literature Search - A.S., E.K.; Writing - A.S.; Critical Reviews - A.K., E.K. 
Conflict of Interest: The authors have no conflicts of interest to declare.

Financial Disclosure: The authors declared that this study has received no financial support.

\section{REFERENCES}

1. Majzoub JA, Srivatsa A. Diabetes insipidus: Clinical and basic aspects. Pediatr Endocrinol Rev. 2006;4 Suppl I:60-65.

2. Ferlin MLS, Sales DS, Celini FPM, Martinell Jr CE. Central diabetes insipidus: Alert for dehydration in very low birth weight infants during the neonatal period. Sao Paulo Med J. 2015;133:60-63.

3. Thakore $P$, Dunbar AE, Lindsay EB. Central diabetes insipidus: $A$ rare complication of $\mathrm{IVH}$ in a very low birth weight preterm infant. J Neonatal Perinatal Med. 2019;12:103-107. [CrossRef]

4. Hanta D, Torer B, Temiz F, Kilicdag H, Gokce M, Erdogan O. Idiopathic central diabetes insipidus presenting in a very low birth weight infant successfully manage with lyophilized sublingual desmopressin. Turk J Pediatr. 2015;57:90-93.

5. Lorenz JM. Fluid and electrolyte therapy in the very lowbirthweight neonate. NeoReviews. 2008;9(3):102-I08. [CrossRef]

6. Molnar Z, Sotiridou E, Dixon H, Ogilvy-Stuart A. Transient diabetes insipidus in a very-low-birthweight preterm infant with intraventricular haemorrhage. Acta Paediatr. 2012;101:389-390.

7. Greger NG, Kirkland RT, Clayton GW, Kirkland JL. Central diabetes insipidus. 22 years' experience. Am J Dis Child. 1986;140:55I-554. [CrossRef]
8. Djermane A, Elmaleh $M$, Simon D, Poidvin A, Carel JC, Léger J. Central diabetes insipidus in infancy with or without hypothalamic adipsic hypernatremia syndrome: Early identification and outcome. J Clin Endocrinol Metab. 2016;10I(2):635-643. [CrossRef]

9. Werny D, Elfers C, Perez FA, Pihoker C, Roth CL. Pediatric central diabetes insipidus: Brain malformations are common and few patients have idiopathic disease. J Clin Endocrinol Metab. 2015;100(8):3074-3080. [CrossRef]

10. Karthikeyan A, Abid N, Sundaram PC, et al. Clinical characteristics and management of cranial diabetes insipidus in infants. J Pediatr Endocrinol Metab. 2013;26:104|-1046.

II. Dabrowski E, Kadakia R, Zimmerman D. Diabetes insipidus in infant and children. Best Pract Res Clin Endocrinol Metab. 2016;30(2):317328. [CrossRef]

12. Korkmaz HA, Demir K, Kılıç FK, et al. Management of central diabetes insipidus with oral desmopressin lyophilisate in infants. $J$ Pediatr Endocrinol Metab. 2014;27:923-927.

13. De Waele K, Cools M, De Guchtenaere A, et al. Desmopressin lyophilisate for the treatment of central diabetes insipidus: First experience in very young infants. Int J Endocrinol Metab. 2014;12:el6120.

14. Ozaydin E, Aycan Z, Yusufoğlu AM, et al. Management of central diabetes insipidus with oral desmopressin in a patient with ectrodactyly and cleft lip/palate (ECP) syndrome. Turk J Pediatr. 2009;51:89-93.

15. Atasay B, Berberoğlu M, Günlemez A, et al. Management of central diabetes insipidus with oral desmopressin in a premature neonate. J Pediatr Endocrinol Metab. 2004;17:227-230. 